This item was submitted to Loughborough's Research Repository by the author.

Items in Figshare are protected by copyright, with all rights reserved, unless otherwise indicated.

\title{
Chemical and topographical effects on cell differentiation and matrix elasticity in a corneal stromal layer model
}

PLEASE CITE THE PUBLISHED VERSION

https://doi.org/10.1002/adfm.201200655

\section{PUBLISHER}

(c) Wiley-VCH

VERSION

AM (Accepted Manuscript)

\section{PUBLISHER STATEMENT}

This work is made available according to the conditions of the Creative Commons Attribution-NonCommercialNoDerivatives 4.0 International (CC BY-NC-ND 4.0) licence. Full details of this licence are available at: https://creativecommons.org/licenses/by-nc-nd/4.0/

\section{LICENCE}

CC BY-NC-ND 4.0

\section{REPOSITORY RECORD}

Wilson, Samantha L., lan Wimpenny, Mark Ahearne, Saaeha Rauz, Alicia J. El Haj, and Ying Yang. 2019. "Chemical and Topographical Effects on Cell Differentiation and Matrix Elasticity in a Corneal Stromal Layer Model”. figshare. https://hdl.handle.net/2134/26833. 
DOI: 10.1002/adfm.((please insert DOI)

\section{Chemical and Topographical Effects on Cell Differentiation and Matrix Elasticity in a} Corneal Stromal Layer Model

By Samantha L. Wilson, Ian Wimpenny, Mark Ahearne, Saaeha Rauz, Alicia J. El Haj* and Ying Yang*

[*] Prof. A.J. El Haj, Dr. Y. YangCorresponding-Author Miss S.L. Wilson, Dr. I. Wimpenny, Dr. M. Ahearne Institute for Science and Technology in Medicine, School of Medicine Keele University Stoke-on-Trent, ST4 7QB (UK)

E-mail: a.j.el.haj@bemp.keele.ac.uk,y.yang@bemp.keele.ac.uk

Dr. S. Rauz

Birmingham and Midland Eye Centre, City Hospital Birmingham, B18 7QU (UK)

Keywords: Keratocytes, cornea, nanofibers, differentiation, modulus 
Submitted to
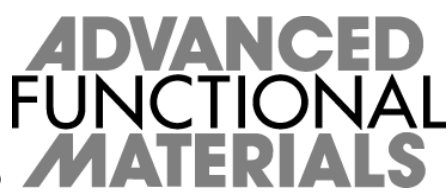

Control and maintenance of the keratocyte phenotype is vital to developing in vitro tissue engineered strategies for corneal repair. In this study the influence of topographical and chemical cues on the mechanical, phenotypical and genotypical behaviour of adult human derived corneal stromal (AHDCS) cells in three dimensional (3D) multi-layered organised constructs is examined. Topographical cues are provided via multiple aligned electrospun nanofiber meshes, which are arranged orthogonally throughout the constructs and are capable of aligning individual cells and permitting cell migration between the layers. The influence of chemical cues is examined using different supplements in culture media. A non-destructive indentation technique and optical coherence tomography are used to determine the matrix elasiticity (elastic modulus) and dimensional changes respectively. These measurements were indicative of changes in cell phenotype from contractile fibroblasts to quiescent keratocytes over the duration of the experiment and corroborated by qPCR. Constructs containing nanofibers have a higher initial modulus, reduced contraction and organised cell orientation compared to those without nanofibers. Cell-seeded constructs cultured in serum-containing media increased in modulus throughout the culture period and underwent significantly more contraction than constructs cultured in serum-free and insulin-containing media. This implies that the growth factors present in serum promote a fibroblast-like phenotype; qPCR data further validates these observations. These results indicate that the synergistic effect of nanofibers and serum-free media plus insulin supplementation provide the most suitable topographical and chemical environment for reverting corneal fibroblasts to a keratocyte phenotype in a 3D construct. 


\section{Introduction}

Submitted to

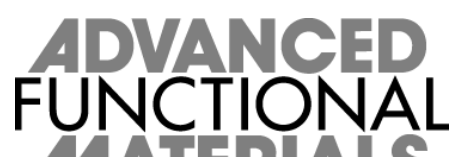

The cornea is a transparent, avascular, ${ }^{[1,2]}$ multilaminar structure ${ }^{[3]}$ that forms a barrier to protect the intraocular structure and microenvironment, while refracting light onto the retina. ${ }^{[3]}$ The integrity of the cornea is essential for preserving vision ${ }^{[4]}$ and is controlled by tissue architecture, cellular morphology and extracellular matrix (ECM) composition and synthesis. The cornea comprises of five distinct layers; corneal epithelium, bowman's layer, stroma, descements membrane and the corneal endothelium. In a healthy cornea, quiescent keratocytes inhabit the corneal stromal layer. ${ }^{[5,6,9]}$ They express high levels of aldehyde dehdrogenase $\left(\mathrm{ALDH}_{3}\right)$ and the proteoglycan keratocan and demonstrate a dendritic phenotype. Their primary function is to metabolise and maintain the stromal ECM. ${ }^{[9]}$ Injury to the corneal stroma can cause changes in keratocyte behaviour leading to a fibroblastic phenotype, resulting in changes in matrix metabolism and contraction of the tissue. ${ }^{[10,11]} \mathrm{A}$ subpopulation of myofibroblasts can form among corneal fibroblasts. These are larger, less mobile and exert greater contractile forces on a tissue in comparison to a fibroblast. ${ }^{[12]}$ Myofibroblasts are characterised by the presence of actin fibers, including $\alpha$-smooth muscle actin $(\alpha-S M A)^{[12,13]}$ which help to convey contractile properties of the cell. ${ }^{[7,13]}$

Previously, our group have investigated the effect of microtopographical cues on AHDCS cells in monolayer culture to determine whether they can influence the orientation and ECM matrix production in vitro. ${ }^{[14]}$ This pilot study revealed that microstructural cues supplied by grooved polycaprolactone films could influence the orientation and gene expression of AHDCS cells. We endeavour to expand on this work and incorporate some of our findings into a 3D multi-layered organised assembly. Previous experiments have shown that differentiation of corneal myofibroblasts to a fibroblast phenotype is possible, ${ }^{[8]}$ but it is uncertain if fibroblasts can differentiate into a keratocyte phenotype ${ }^{[8]}$ Conditioned media has 
Submitted to

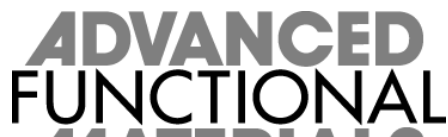

been effective for the differentiation of various cell lines; however, the optimal use of supplements and additives for corneal cell culture is yet to be fully defined. Acetycholine, ${ }^{[6]}$ ascorbic acid, ${ }^{[15]}$ insulin, ${ }^{[6,16]}$ growth factors ${ }^{[6]}$ and cytokines ${ }^{[5]}$ are amongst many supplements investigated when attempting to obtain a "pure" proliferating culture of keratocytes. These studies on biochemical cues are often performed under simplified two-dimensional (2D) tissue culture conditions. In addition, the role of topographical cues on keratocytes differentiation behaviour, in particular in a 3D environment, has not been fully established. Naturally, keratocytes grow in an orthogonally arranged architecture, following the organisation of the collagen fiber bundles. Even in 2D culture conditions, keratocyte populations are able to align in multiple adjacent layers arranged $30-90^{\circ}$ to each other. ${ }^{[14,15]}$ Wray et al. ${ }^{[17]}$ and $\mathrm{Wu}$ et $a .^{[18]}$ have previously used aligned collagen and poly(ester urethane) urea fibers fabricated by electrospinning, to grow corneal stromal cells. However, these studies were limited to a single dense nanofiber sheet and did build the full organisation similar to that of the native tissue. In order to generate a functional corneal tissue, a 3D environment with defined topographical cues throughout a 3D construct is required.

The aim of this study is to investigate a topographical nanofiber layered 3D approach which aspires to influence cell phenotype from fibroblasts into keratocytes. This model allows us to investigate the relationship between media and topography synergistically in a 3D model both of which have previously been shown to influence cell phenotype in 2D monolayer culture. ${ }^{[14,15]}$ Our non-destructive monitoring tools developed in recent years ${ }^{[19,20,21]}$ were utilized to reveal how biochemical ingredients and topographic features of scaffolds affect stromal cell differentiation in terms of contraction, migration and mechanical properties in a 3D environment for prolonged culture periods. These results have then been corroborated with microscopic and genotypic characterisation of the cell phenotype. 


\section{Results}

Submitted to
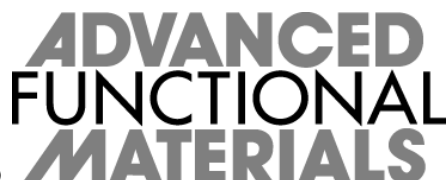

\subsection{Cellular contraction}

Collagen hydrogel constructs were produced with and without poly (L,D lactic acid) (PLDLA) electrospun nanofibers and then cultured in serum-containing fibroblast (F) media supplemented with L-Glutamine, and antibiotic and antimitotic solution; or one of two serumfree keratocyte medias supplemented with ascorbic acid and either insulin or basic Fibroblast Growth Factor ( $\beta$-FGF), respectively (K or $\mathrm{K}^{*}$ ). Through a layer-by-layer fabrication protocol (Fig. 1), the fragile nanofiber meshes have been successfully incorporated into the collagen constructs and the majority of the AHDCS cells were attached to the nanofibers in an orthogonal arrangement following the nanofiber assembly at the initial stage. The surface area of non-confined constructs seeded with AHDCS cells was monitored every 24 hrs for 7 days to determine whether chemical cues and/or topographical cues influence the contraction of the constructs (Fig. 2). The removal of the filter paper ring allowed constructs to contract in all directions, thus altering the surface area and total volume of a construct as a whole.

Digital photography was used to image the constructs and the percentage change in surface area was calculated relative to their initial surface area (Fig. 2). A significant amount of contraction was observed in the constructs cultured in F media. The surface area of the constructs were reduced to less than $20 \%$ of its original surface area and became opaque in appearance. Although the fiber-containing constructs cultured in F media did contract, the change in surface area was not a prominant and they retained more than $50 \%$ of their original surface area. The fiber-containing constructs cultured in both $\mathrm{K}$ and $\mathrm{K}^{*}$ media maintained $80 \%$ of their surface area following 7 days culture. There was no significant difference in contraction of fiber-containing cellular constructs cultured under either serum-free media for the duration of the experiment. The construct surface area remained constant in all acellular 
Submitted to
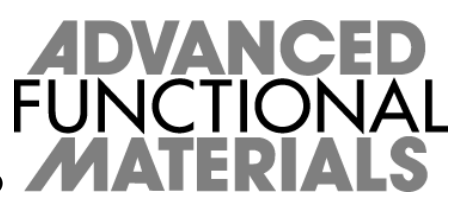

control specimens manufactured with and without the inclusion of fibers and cultured in $\mathrm{F}, \mathrm{K}$ and $\mathrm{K}^{*}$ media respectively.

The contraction in confined constructs was limited to a change in thickness. The change in thickness of the constructs was measured using optical coherence topography (OCT ${ }^{[21]}$ over 14 days (Fig. 3). The thickness of all cellular constructs cultured in serum-free keratocyte media remained constant throughout the duration of the experiment. The cellular constructs cultured in F media contracted thus making the constructs thinner. Contraction predominantly occurred within the first week. ANOVA tests revealed that presence of fibers and the supplementation of culture media had a significant effect on the change in thickness of the construct $(\mathrm{p} \leq 0.01)$. After 3 days in culture, constructs cultured without fibers in F media significantly reduced in thickness compared to all other constructs ( $p \leq 0.001$ ). Fiber containing constructs cultured in F media contracted significantly more compared to other fiber containing constructs but contracted significantly less than the constructs without fibers also in F media. No significant difference in the change of hydrogel thickness was observed between the cellular constructs (with and without fibers) compared to their acellular controls when cultured in $\mathrm{K}$ and $\mathrm{K} *$ media. The construct thickness of all acellular control specimens remained constant.

\subsection{Modulus measurement}

The elastic modulus of confined constructs was measured every 3-4 days for 14 days. The modulus of constructs cultured in F media without fibers was significantly greater $(\mathrm{p} \leq 0.001)$ than the constructs without fibers cultured in $\mathrm{K}$ and $\mathrm{K}^{*}$ media from day 3 onwards and significantly lower $(\mathrm{p} \leq 0.001)$ than all fiber-containing constructs $(\mathrm{p} \leq 0.05$ for acellular gels in F media vs. cellular gels in $\mathrm{K}^{*}$ media at day 14, Fig. 3). The modulus of fiber-containing 
Submitted to
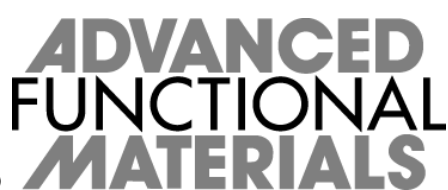

constructs cultured in F media was statistically greater ( $\mathrm{p} \leq 0.01$ at day $3, \mathrm{p} \leq 0.001$ from days 7-14) than fiber containing constructs cultured in both $\mathrm{K}$ and $\mathrm{K}^{*}$ media. There was no significant difference observed in the modulus of constructs cultured in $\mathrm{K}$ and $\mathrm{K}^{*}$ media, with or without fibers throughout the experiment. There was an initial increase in modulus following 3 days culture period from approximately $3.6 \mathrm{kPa}$ to $5 \mathrm{kPa}$ and then the modulus remained constant for the remainder of the experiment.

All acellular control hydrogels retained a constant modulus between 0.5 and $1 \mathrm{kPa}$. All acellular constructs cultured with fibers had a significantly higher modulus (2.5-3 kPa) than the corresponding fiber-free constructs $(\mathrm{p} \leq 0.001)$. The modulus of all fiber-containing constructs were significantly greater $(\mathrm{p} \leq 0.001)$ than those without.

\subsection{Cell viability and morphology}

All constructs, with and without fibers, confined and non-confined, in all medias maintained high cell viability. Organisation of the cells was observed via fluorescent microscopy and allowed for the alignment of the cells on the nanofibers to be visualised as opposed to the random orientation of the cells in non-fiber containing constructs (Fig. 4). In all media types, cells were organised orthogonally in a 3D arrangement in accordance with the nanofibers orientation within a particular layer.

Phalloidin tetramethyylrhodamine-B-isothiocyanate labeling of cells in confined constructs at day 14 revealed that the cells in F media were larger and more fusiform in morphology in comparison to cells cultured in $\mathrm{K}$ and $\mathrm{K}^{*}$ media which were much thinner and more elongated (Fig. 5B-D).

The cellular aspect ratios in $\mathrm{F}$ media specimens were significantly lower than those in $\mathrm{K}$ and K* media with and without nanofibers, both a day 7 and 14 day culture period (Fig. 5A). 
Submitted to

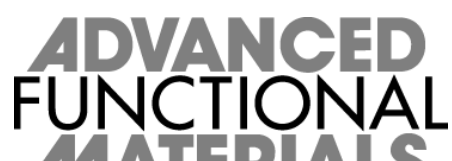

Furthermore, the aspect ratios in the specimens with nanofibers were higher than the nanofiber-free counterparts in all culture media and at both day 7 and 14 . The enhanced effect of nanofibers on the aspect ratio was greater in keratocyte culture media ( $\mathrm{K}$ and $\mathrm{K}^{*}$ ) than in fibroblast culture media (F media). The aspect ratio was highest for cells cultured in fibercontaining constructs in $\mathrm{K}$ media for 14 days. Increasing the culture time resulted in an increased aspect ratio for all the specimens.

\section{4. qPCR gene expression}

In order to determine whether the 3D collagen environment and nanofibers had an effect on the expression of genetic markers, AHDCS cells were cultured in 2D monolayer (on Tissue Culture Plastic, TCP) and were compared to the cells cultured in 3D constructs, with and without the inclusion of nanofibers in fibroblast (F) culture media (Fig. 6). Following 7 days culture, there was no significant difference in the expression of keratocan and $\mathrm{ALDH}_{3}$ in fiber-free or fiber-containing constructs. However, the fibroblastic marker Thy-1 was significantly down-regulated in both fiber-free and fiber-containing constructs $(p \leq 0.01$ and $p$ $\leq 0.05$, respectively). Additionally, in the fiber-containing constructs, fibroblastic marker $\alpha$ SMA was also down-regulated significantly $(\mathrm{p} \leq 0.05)$. Similar trends were observed after 14 days culture in that there was no significant difference in the expression of the keratogenic markers, but Thy-1 was further down-regulated both in fiber-containing and fiber-free constructs $(\mathrm{p} \leq 0.01)$ and $\alpha$-SMA was further down-regulated in the fiber containing constructs $(\mathrm{p} \leq 0.01)$.

When cultured in $\mathrm{K}$ and $\mathrm{K}^{*}$ media for 7 days, there was no significant difference in the expression of keratocan when comparing fiber-free and fiber-containing 3D constructs (Fig. 7). However, when cultured in $\mathrm{K}$ media, the expressions of Thy- 1 and $\alpha$-SMA were at 
Submitted to

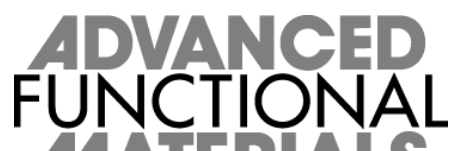

significantly lower levels ( $\mathrm{p} \leq 0.01$ and $\leq 0.05$ respectively compared to $\mathrm{K}^{*}$ ), and $\mathrm{ALDH}_{3}$ at significantly higher levels $(\mathrm{p} \leq 0.001)$ in the fiber-containing constructs. $\mathrm{ALDH}_{3}$ was also expressed in significantly higher levels $(\mathrm{p} \leq 0.05)$ in the fiber-containing constructs cultured under $\mathrm{K}^{*}$ media.

It was apparent that culture time was having an effect on the reduced expression of fibroblastic markers and increased expression of keratogenic markers in both fiber-free and fiber-containing constructs. When cultured in F media there was only a significant reduction in expression of Thy-1 ( $\mathrm{p} \leq 0.05)$ when comparing day 7 and day 14 fiber-free constructs. However, in the fiber-containing constructs both Thy-1 and $\alpha$-SMA expression was significantly lower ( $\mathrm{p} \leq 0.05$ and 0.01 , respectively) at 14 days culture. Culture time appeared to have the most significant effect in the fiber-free constructs when cultured under serum-free media (i.e. $\mathrm{K}$ and $\mathrm{K}^{*}$ ). When cultured under $\mathrm{K}$ media there was a significant decrease in expression of Thy- 1 and $\alpha$-SMA ( $\mathrm{p} \leq 0.05$ and $\leq 0.001$, respectively) and a significant increase in $\mathrm{ALDH}_{3}$ expression $(\mathrm{p} \leq 0.001)$. Similar trends were also observed in $\mathrm{K}^{*}$ media. Culture time appeared to have an exclusively significant effect on $\mathrm{ALDH}_{3}$ expression in fibercontaining constructs $(\mathrm{p} \leq 0.001)$. Other genes did not show this trend.

\section{Discussion}

Obtaining sufficient numbers of stromal cells with a keratocyte phenotype is a central challenge in the in vitro regeneration of a corneal stroma. By nature, keratocytes are quiescent, i.e. not proliferative, hence it is difficult to obtain a high population while maintaining the keratocyte phenotype. Sufficient numbers of stromal cells can be obtained from dissected corneal rims, by allowing the cells to adopt a fibroblastic phenotype. In this study, we demonstrated that corneal fibroblasts can differentiate back towards a keratocyte phenotype in 
Submitted to
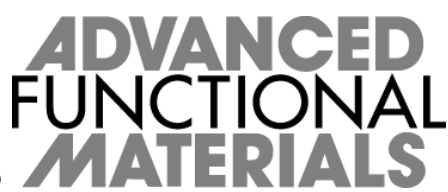

a 3D structure by controlling the chemical and topographic environment. The elastic modulus measurements enabled us to reveal the effect of the differentiation process over a prolonged culture and the corresponding phenotype of the AHDCS cells have been defined by qPCR at 7 and 14 days.

\subsection{The chemical cue effect}

The addition of serum to culture media results in the differentiation of keratocytes to fibroblasts. ${ }^{[8,10,23]}$ Previous studies have shown that when cultured in serum-free media, stromal cells maintain a quiescent phenotype. ${ }^{[8,10,23]}$ However, quiescence alone is not sufficient in determining a keratocyte phenotype as often the removal of serum from media results in quiescence followed by apoptosis. Thus supplementation is required in media that can promote cell growth and proliferation without encouraging fibroblastic differentiation.

Insulin was used as a supplement in the $\mathrm{K}$ culture media as it has been suggested that it is useful in maintaining keratocyte phenotype and cell viability in in vitro cultures. ${ }^{[5,22]}$ The addition of insulin to in vitro cultures resulted in elongated cell morphology, maintained keratocan expression and quiescence. Our results are consistent with these studies, confirming that the inclusion of insulin and ascorbate in keratocyte media is also valid in a 3D structured environment for the control of stromal cell phenotype.

In contrast, $\beta$-FGF was the main supplement in $\mathrm{K}^{*}$ culture media, which has previously been used to differentiate and expand human corneal stromal stem cells (hCSSC) in monolayers. ${ }^{[24,25]}$ It has been reported that when cultured in this media, hCSSCs expressed the genetic markers unique to the keratocyte genotype (keratocan and keratan sulphate), ${ }^{[24,25]}$ but they lacked the degree of organisation required to mimic the ECM of the corneal stromal layer. The addition of $\beta$-FGF to keratocyte culture media has also been shown to reduce the 
Submitted to

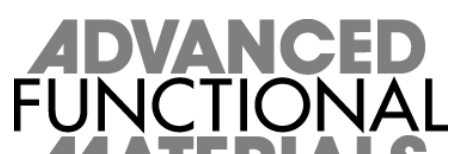

expression of $\alpha$-SMA and increase keratan sulphate expression. ${ }^{[5]}$ The reduced expression of $\alpha$-SMA suggests that $\beta$-FGF is capable of blocking differentiation towards a myofibroblast phenotype. Our study confirmed that in $\beta$-FGF-containing media, AHDCS cells retained a keratocyte-like phenotype in a 3D structured environment.

When comparing the use of $\mathrm{K}$ and $\mathrm{K}^{*}$ media, it was apparent that $\mathrm{K}$ media was preferable for restoring characteristic markers of keratocytes, manifested by the cell aspect ratio and qPCR data. The combination of ascorbate and insulin in culture media has been shown to stimulate collagen synthesis and increase keratocan and lumican accumulation. ${ }^{[22]}$ The insulincontaining $\mathrm{K}$ media encouraged cells to become significantly more elongated than the cells cultured in $\mathrm{K}^{*}$ media, facilitating the cells to become closer to the desired elongated morphology of a native keratocyte. Our study suggests that through the suppression of proliferation rate of fibroblasts and using appropriate supplements in culture media, the partial restoration of the keratocyte phenotype following a fibroblastic transition, is possible.

\subsection{The topographical effect}

Native corneal tissue primarily consists of collagen type I. Collagen type I hydrogels formed by conventional thermal gelation often have poor mechanical strength and lack organisation, which is contrary to the characteristics of native stroma. ${ }^{[26]}$ In order to rectify this problem we implemented a facile new technique in this study to align AHDCS cells through incorporating polymeric nanofibers into collagen hydrogel constructs. The addition of nanofibers acted as a contact guidance platform, on which, cells could orientate and elongate. Our protocol enabled us to construct multiple lamellae and alter the organisation of the cells through the whole construct thickness, with a tuneable distance between the layers. The novelty of our protocol is using portable meshes fabricated by a smart parallel electrode collector. These meshes have high fiber alignment and relative low fiber density (average line density of 45 nanofiber/100 
Submitted to
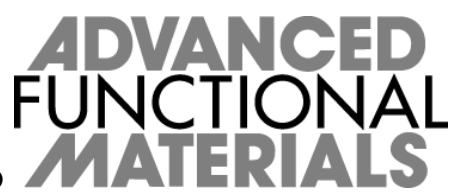

$\mu \mathrm{m}$ and a thickness ranging between 0.5 and $3.0 \mu \mathrm{m}$ ) whilst remaining transportable. ${ }^{[27]}$ The nanofiber meshes enabled us to align individual cells in the desired orientation and also permitted the cells to penetrate between layers when multiple nanofibrous meshes, were used.

The incorporation of orientated nanofiber layers clearly influenced cell organisation and morphology in our 3D constructs. Observations via fluorescent microscopy demonstrated that the orthogonal arrangement of cells was not confined to one plane, rather, that the cells were on three different planes. It was considered that the altered cell morphology of the AHDCS cells (higher aspect ratio), had induced the changes in the gene and protein expression within the cells. Two mechanisms may be used to explain this topographic cue effect, i.e. the influence of nanofibers on the alteration of the modulus, cell morphology and gene expression of the stromal cells in comparison to collagen only constructs. Firstly, the incorporation of the nanofibers increased the stiffness of the constructs as shown in the acellular constructs, which could potentially induce the AHDCS cells towards a more keratogenic lineage, as it has been previously described that substrate stiffness can affect differentiation of stem cells. ${ }^{[28]}$ Secondly, the attachment of cells to the nanofibers reduced the cells ability to contract the surrounding collagen. As the nanofibers were stiffer than the collagen, once attached the stromal cells either stopped cellular contraction due to sensing the stiffer substrate or were physically unable to deform the substrate. Reducing the contraction of the construct could be associated with promoting a keratocytic lineage.

\subsection{Interactions between the effect of chemical and topographical cues}

Both the use of F media and the incorporation of nanofibers produced constructs with a higher modulus. However, the cells cultured in $\mathrm{K}$ and $\mathrm{K}^{*}$ media did not appear to have much of an effect on the elastic modulus of the construct. The hydrogel constructs that contained cells had 
Submitted to
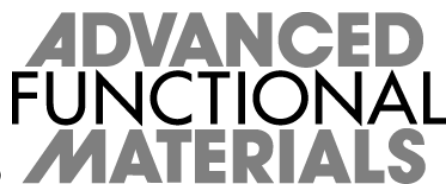

a modulus that was very similar to the acellular constructs containing fibers in keratocyte media. This supports the hypothesis that the cells were behaving in a quiescent manner and were not exerting a contractile force on the hydrogel construct. In serum-containing media, the presence of nanofibers in constructs reduced the cell contraction to a certain extent when compared to the fiber-free counterpart. The most significant reduction in cell contraction occurred in the specimens cultured in $\mathrm{K}$ and $\mathrm{K}^{*}$ media, implying nanofibers acted as a topographical cue in combination with chemical cues.

\subsection{The effect of chemical and topographical cues on the gene expression of AHDCS cells}

As quiescence or cell morphology alterations are not unique to the keratocyte phenotype, ${ }^{[5]}$ we corroborated our mechanical findings with traditional qPCR, to examine the gene expression of characteristic markers, specific to a keratocytic genotype. In previous studies lumican, ${ }^{[22,29]}$ keratocan, ${ }^{[22,30]} \mathrm{ALDH}_{3},{ }^{[22,30,31]}$ Thy-1, ${ }^{[9,32,33]} \alpha$-SMA, ${ }^{[5,6,8,13,34]}$ fibronectin, ${ }^{[5]}$ CD34 ${ }^{[34]}$ and vimentin ${ }^{[35]}$ have all been examined to help to determine and distinguish the differences in gene and protein expression between corneal keratocytes, fibroblasts and myofibroblast phenotypes in in vitro cultures. In this study, we chose to monitor the gene expression profiles of four markers, keratocan, $\mathrm{ALDH}_{3}$, Thy- 1 and $\alpha$-SMA in response to the chemical and topographical cues. We observed two interesting phenomena. Firstly, AHDCS cells did not entirely lose their keratocyte gene expression, even being cultured in serumcontaining media for two weeks. Secondly, the relative expression of keratocyte and fibroblast marker genes could be affected by chemical and topographical factors. Three cues were investigated alone, and in combination in this current study. Simply changing from 2D (TCP) to 3D (collagen hydrogel) culture conditions in fibroblast media increased the gene expression of keratocyte markers. This alteration of the gene expression pattern was more 
Submitted to
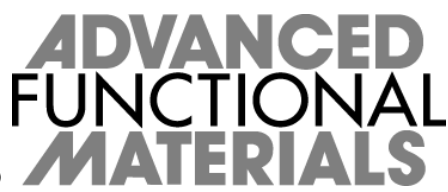

obvious in the fiber-containing collagen constructs cultured in fibroblast medium. Both Keratocan and $\mathrm{ALDH}_{3}$ gene expression were significantly up-regulated, whilst Thy-1 and $\alpha$ SMA were significantly down-regulated. Furthermore, the alteration of supplements in culture media encouraged gene expression toward a keratocytic phenotype. Fibroblast gene expression was suppressed in both $\mathrm{K}$ and $\mathrm{K}^{*}$, serum-free medium. The presence of nanofibers in the constructs made the effect of the chemical supplements more prominent.

In vivo healthy keratocytes characteristically express high levels of keratan sulphate associated molecules lumican (glycoprotein) and keratocan (proteoglycan). ${ }^{[22]}$ Whilst lumican is found in many tissues, ${ }^{[22]}$ keratocan is exclusive to the cornea. ${ }^{[22]}$ Keratocan expression decreases during wound healing, which is the phase associated with fibroblastic activity and contraction of the wound. $\mathrm{ALDH}_{3}$ is expressed in high levels in a healthy keratocyte. ${ }^{[22]}$ When cultured in the presence of serum, which is associated with differentiation of keratocytes towards fibroblastic lineage, the expression of $\mathrm{ALDH}_{3}$ is reduced or lost. Therefore, this gene served as a marker for keratocyte phenotype. The glycoprotein Thy- 1 is not expressed in uninjured corneal tissue or isolated keratocytes. Both myofibroblasts and fibroblasts express Thy- $1^{[9]}$ and it is regularly used in corneal tissue engineering applications to help distinguish corneal fibroblasts from keratocytes ${ }^{[9,32,33]}$ In addition, corneal wound fibroblasts and myofibroblasts express $\alpha$-SMA, which is linked to wound contraction. ${ }^{[6,8,13]}$ Therefore, expression of $\alpha$-SMA is associated with keratocytes towards fibro/myofibroblastic lineages. The qPCR results in our study demonstrate that the four genes selected were effective at determining the effect of culture conditions (chemical cues) and nanofibers (topographical cues) on the phenotype of AHDCS cells. 
Submitted to
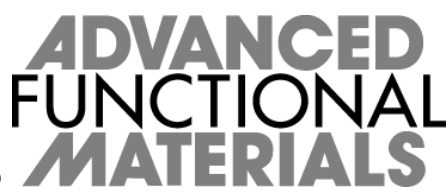

The gene data corresponded well with elastic modulus data in that the nanofibers were able to suppress the fibroblastic tendencies of the stromal cells cultured under serum-containing media, while serum-free media were capable of altering the keratocyte gene expression. The differences in gene expression correlated with the contractile nature of the cells, with high levels of fibroblastic markers being expressed with increased contraction. Previous studies ${ }^{[17,18,22]}$ in $2 \mathrm{D}$ culture conditions have shown that media conditions and topographical cues can stimulate the up-regulation of genetic markers associated with a keratocytic phenotype and switch off fibroblastic gene expression. Our studies demonstrated a cumulative, combined effect of media and topographical stimulation towards maintaining a keratocytic phenotype and gene expression. Switching from 2D monolayer culture to a 3D collagen environment and then to an organised 3D environment has an observable effect on the AHDCS cell lineage, which can be manipulated to improve current corneal tissue engineering models.

\section{Conclusions}

It has been demonstrated that chemical and topographical cues can be used to manipulate the phenotype of AHDCS cells in vitro in 3D corneal model constructs. Tailoring the culture environment can encourage these cells towards a keratocyte or fibroblast lineage and these phenotypes are interchangeable. The addition of serum causes AHDCS cells to become fibroblastic, but removal of serum or introducing stiff and orthogonally arranged nanofiber layers cause the cells to return to a keratocyte-like morphology. The combined effect of the chemical and topographical cues could represent an opportunity for developing new regenerative strategies for corneal repair and regeneration. The combination of nondestructive monitoring techniques and analysis of gene expression provide important feedback for optimizing culture conditions, which has not previously been shown in 3D corneal models. 


\section{Submitted to}

\section{Experimental}

Fabrication of portable nanofibers: Electrospinning was used to fabricate portable poly (L,D lactic acid) (PLDLA, 96\%L/4\%D; Purac B.V. Netherlands) aligned nanofibers as previously described [27]. Briefly, PLDLA (2\%) solution was made in a mixing solvent (chloroform and dimethylformamide in a 7:3 ratio, Sigma-Aldrich, UK). A syringe pump (KR Analytical, UK) was used to feed the polymer solution $\left(0.025 \mathrm{ml} \mathrm{min}^{-1}\right)$ through a blunt $18 \mathrm{G}$ needle (KR Analytical, Sandbach, UK). The needle was connected to a High Voltage Power Supply (Spellman HV, UK) which comprised two power supplies, one positive and one negative. The polymer solution was positively charged and the collector negatively charged. Fibers were collected using a portable collector consisting of a non-conductive frame (30 x $10 \mathrm{~cm}$ ) with 2 sheets of thin steel 'blades' arranged parallel $4 \mathrm{~cm}$ apart. The fibers were collected over a width of approximately $10 \mathrm{~cm}$. The collector was electrically connected to a static copper plate. The distance between the needle tip and the portable collector was $20 \mathrm{~cm}$; the distance between the portable collector and the static copper plate was $10 \mathrm{~cm}$. The electrospinning duration was $10 \mathrm{~min}$. The nanofibers were collected by adhering the aligned fibers to a square cellulose acetate frame $\left(16 \mathrm{~cm}^{2}\right)$ so that the relatively low density nanofibers mesh could be handled. The density of fibers was measured using a technique described previously [27] as approximately 45 nanofibers $/ 100 \mu \mathrm{m}$ and had a thickness ranging from 0.5 to $3.0 \mu \mathrm{m}$ [27] (Fig. 1).

Adult human derived corneal stromal cell culture: Adual human corneal tissue remaining from corneal transplantation was used for the isolation of AHDCS cells. This research has received approval from Birmingham NHS Health Authority Local Research Ethics Committee. Informed signed consent was obtained from the donors. The endothelial and 
Submitted to

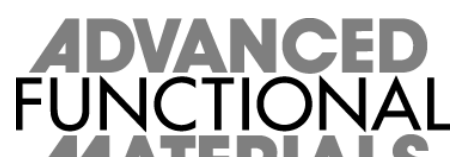

epithelial layers were stripped using sharp-point forceps. The remaining stromal layer was cut into smaller pieces and cultured in cell culture flasks containing Dulbelcco's modified eagle medium (DMEM; Biowest, France) supplemented with foetal calf serum (10\%; FCS, Biowest, France), antibiotic and antimitotic solution (1\%; A+A, Sigma-Aldrich, UK) and L-Glutamine (2 mM; Sigma-Aldrich, $\mathrm{UK}$ ) at $37^{\circ} \mathrm{C}, 5 \% \mathrm{CO}_{2}$, allowing stromal cells to migrate out from the tissue. Media was changed every 2-3 days and the cells were passaged at confluence. Third passage corneal stromal cells were used for experiments.

Hydrogel fabrication: Rat tail collagen type I (BD Bioscience, Mountain Science, CA) hydrogels was prepared according to the manufacturer's instructions, using 10x DMEM in place of PBS. Collagen mixture $\left(500 \mu \mathrm{l}\right.$ at $\left.3.5 \mathrm{mg} \mathrm{ml}^{-1}\right)$ was cast into a filter paper ring (internal diameter $20 \mathrm{~mm}$ ) on non-adherent PTFE plates. Gelation was achieved by incubation at $37^{\circ} \mathrm{C}, 5 \% \mathrm{CO}_{2}$ for $30-45$ mins. For construction of hydrogels containing nanofibers, three layers of electrospun PLDLA aligned fibers per construct were assembled in an orthogonal arrangement with a filter paper ring and acetate square between each layer acting as spacers (Fig. 1).

Cell seeding of constructs: AHDCS cells $\left(0.5 \times 10^{6}\right.$ per construct suspended in $300 \mu$ l media) were seeded directly onto the nanofiber layers. The cells were allowed to attach for at least 2 hrs. After the initial attachment stage, collagen solution (500 $\mu \mathrm{l}$ at $3.5 \mathrm{mg} \mathrm{ml}^{-1}$ ) was added to the cellular fiber-containing construct and allowed to infiltrate through the fibers, which stabilised the fiber layers. In the fiber-free constructs the cells were suspended throughout the

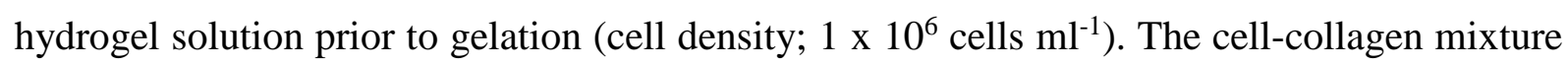
(500 $\mu \mathrm{l}$ ) was cast for each construct. 
Submitted to
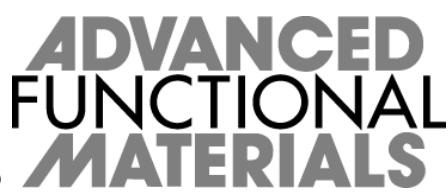

Conditioned culture media: Three different types of media, one fibroblast media (F media) and two different serum-free keratocyte medias, (K media and $\mathrm{K}^{*}$ media), were investigated. F media was DMEM supplemented with FCS (10\%), A+A (1\%) and L-Glutamine (2 mM). K media consisted of DMEM-F12 (Biowest, France), supplemented with ascorbic acid (1 mM; Sigma-Aldrich, UK), A+A (1\%) and insulin (1 $\mu \mathrm{g} \mathrm{ml}^{-1}$; Sigma-Aldrich, UK). Advanced keratocyte media (K* media) consisted of Advanced MEM (Gibco, UK) supplemented with ascorbic acid (1 mM) and basic Fibroblast Growth Factor ( $\beta$-FGF (0.01\%); BPS BioScience, UK).

Construct contraction: Hydrogels cast into filter paper rings were effectively confined to the dimension of the filter paper ring. Construct contraction was measured with (confined) and without this ring (non-confined). This permitted analysis of confined contraction in terms of a change of thickness of the hydrogel construct via optical coherence tomography (OCT) [21], constructs were examined every 3 to 4 days over 14 days in culture. Non-confined constructs allowed the constructs to contract in any direction. The central portion of the non-confined constructs was monitored daily for 7 days and images were recorded using digital photography (D5000, Nikon, Japan). Acellular collagen constructs, with and without fibers were produced as a control.

Cell viability and morphology: Cell viability was observed at day 7 and 14 using a live-dead fluorescent double staining kit (Fluka, Switzerland) able to simultaneously stain viable cells green, and dead cells red; it was used according to the manufacturer's instructions. Stained hydrogel constructs were washed in PBS and examined using fluorescent microscopy (Eclipse Ti-S, Nikon, Japan). 
Submitted to

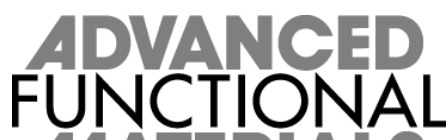

14 A

Cell morphology was observed at day 14 by using phalloidin tetramethyylrhodamine-Bisothiocyanate (Sigma-Aldrich, UK) to fluorescently stain actin filaments. Briefly, each

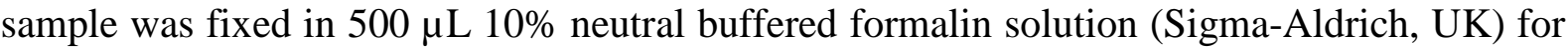
30 mins, before washing 3 times in phosphate buffered saline (PBS Sigma-Aldrich, UK). Samples were then permeabilized with $500 \mu \mathrm{L}$ 0.1\% Triton ${ }^{\circledR}$ X100 for 30 mins. $500 \mu \mathrm{L}$ of a $10 \mu \mathrm{g} / \mathrm{ml}$ phalloidin tetramethyylrhodamine-B-isothiocyanate (Sigma-Aldrich, UK) solution applied to each sample and incubated at room temperature, in the dark for 40 mins. Cell morphology was examined using fluorescent microscopy (Eclipse Ti-S, Nikon, Japan).

The relationship of cell morphology, topography and culture environment was investigated by measuring the aspect ratio of the cells based on the images using ImageJ (NIH, USA). A linedrawing tool was used to measure the extremities of the cell; the long axis of the cell was measured, followed by the width. The ratio length:width was used to determine if the cells had become elongated. An aspect ratio of 1 indicates that the cells were of equal proportions and demonstrated no elongation; an elevated aspect ratio indicates elongation of the cells. Three separate areas per sample were examined and a minimum of 50 cells were measured per sample.

Modulus measurement: The mechanical properties of the constructs were measured at different culture times using a non-destructive spherical indentation technique $[19,20]$ which permitted repeated analysis of constructs over time. Hydrogel constructs were circumferentially clamped. A sphere (0.0711gram and $2 \mathrm{~mm}$ radius) was placed centrally on the construct, caused uniform deformation of the hydrogel. The extent of the deformation was recorded and applied to a theoretical model [36] to calculate the elastic modulus of the constructs. 
Submitted to

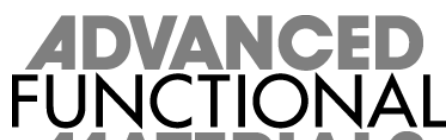

14 A ER ALS

Quantitative polymerase chain reaction ( $(P C R)$ : The constructs were processed for PCR analysis by removal of the filter paper rings; the central portion of the construct was then suspended in $1 \mathrm{ml}$ lysis buffer $(\mathrm{pH} 7)$ containing guanidine thiocyanate (50\% w/v; SigmaAldrich, UK) N-lauryl sarcosine (5\% w/v; Sigma-Aldrich, UK) and $\beta$-mercaptoethanol (0.7\%; Sigma-Aldrich, UK). Similarly, the ADHCS cells grown in monolayer (TCP) were directly treated with the lysis buffer. The mixture was then vortexed for 2-3 mins until completely dissolved. Acid/alcohol (acid phenol/chloroform and isoamyl alcohol) extraction of RNA was performed on ice. The RNA was precipitated and quantified (Nanodrop ND2000; Thermoscientific, UK). RNA $(0.1 \mu \mathrm{g})$ was reverse transcribed to cDNA using the Quantitect Reverse Transcription kit (Qiagen, Crawley, West Sussex) according to the manufacturer's instructions. cDNA gene expression was amplified using the Applied Biosystems assay on demand kit, according to the manufacturer's instructions. TaqMan geneexpression master mix incorporating the primer/probe for the gene of interest (Table 1) were added to sample cDNA $(1 \mu \mathrm{l})$ and tested using an ABI Prism 7000 (Applied Biosystems, UK) instrument. The qPCR reaction underwent 40 amplification cycles. Confluent AHDCS cells grown in monolayer were used as a reference point for comparison, i.e. cellular control. 18S was used as the endogenous control for normalisation of expression levels for the genes of interest using the delta delta $\mathrm{C}_{\mathrm{T}}\left(\Delta \Delta \mathrm{C}_{\mathrm{T}}\right)$ method. Each $\Delta \Delta \mathrm{C}_{\mathrm{T}}$ value was used in the formula $2^{-\Delta \Delta \mathrm{CT}}$ to give a comparative fold change of gene expression level relative to $18 \mathrm{~S}$. Recorded data was averaged and represented as a mean value \pm the calculated standard error.

Statistics: The data was subjected to a normality (Kolmogorov-Smirnoff) test. The data was normally distributed, so comparisons were performed using wither T-tests for pairs of data, or one-way analysis of variance (one-way ANOVA) followed by a Tukey's post-test. 
Submitted to

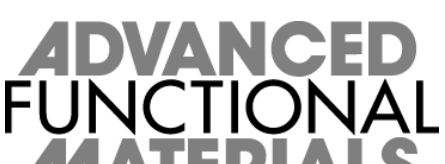

Significance was indicated to determine if the effects of time, media and/or nanofibers were statistically significant at three levels: $* \mathrm{P} \leq 0.05, * * \mathrm{P} \leq 0.01$ and $* * * \mathrm{P} \leq 0.001$.

\section{Acknowledgements}

Funding from the Doctoral Training Centre of Regenerative Medicine, (EPSRC, UK), BBSRC, UK (BB/F002866/1) and the Birmingham Eye Foundation (UK) (Charity 257549) are gratefully acknowledged.

[1] M. Griffith, R. Osborne, R. Munger, X. Xiong, C.J. Doillon, N.L.C. Laycock, M. Hakim, Y. Song and M.A. Watsky, Science. 1999, 286, 2169.

[2] C.R. McLaughlin, R.J.F.Tsai, M.A. Latorre, M. Griffith, Front Biosci. 2009, 14, 3326.

[3] J.W. Ruberti and J.D. Zieske. Prog Retin Eye Res. 2008, 27, 549.

[4] L. Qu, X.Y.Yang, X. Wang, M. Zaoh, S. Mi, Z. Dou, H. Wang. Vet J. 2009, 179, 392.

[5] J. V. Jester and H.C. Jin. Exp Eye Res. 2003, 77, 581.

[6] N. Builles, N. Bechetoille, V. Justin, A. Ducerf, C. Auxenfans, C. Burillon, M. Sergent, O, Damour. Biomed Mater Eng. 2006, 16, 95.

[7] M. E. Fini. Prog Retin Eye Res. 1999, 18, 529.

[8] B. L. Berryhill, R. Kader, B. Kane, D. E. Birk, J. Teng, A. R. Hassell. Invest Ophthalmol Vis Sci. 2002, 43, 3416.

[9] Y. Pei, D. M. Sherry, A. M. McDermott. Exp Eye Res. 2004, 79, 705.

[10] M. P. Beales, J. L. Funderburgh, J. V. Jester, J. R. Hassell. Invest Ophthalmol Vis Sci. 1999, 40, 1658.

[11] J. L. Funderburgh, M. M. Mann, M. L. Funderburgh. J Biol Chem. 2003, 278, 45629.

[12] C. Helary, L. Ovtracht, Coulomb B, G. Godeau, M. M. Giraud-Guille, Biomaterials, 2006, 27, 4443-4452. 
Submitted to

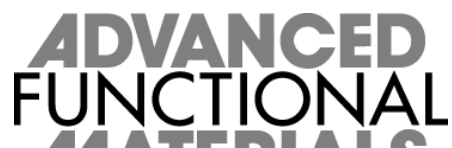

4 A

[13] J. V. Jester, W. M. Petroll, P. A. Barry,H. D. Cavanagh. Invest Ophthalmol Vis Sci. 1995, 36, 809.

[14] K. Then, Y. Yang, M. Ahearne, A. J. El Haj. Curr Eye Res. 2011, 36, 88-93.

[15] X. Q. Guo, A. E. K Hutcheon,S. A. Melotti, J. D. Zieske, V. Trinkaus-Randall, J. W. Ruberti. Invest Ophthalmol Vis Sci. 2007, 48, 4050.

[16] K. Musselmann, B. Kane, B. Alexandrou , J. R. Hassell. Invest Ophthalmol Vis Sci. 2006, 47, 5260 .

[17] L. S. Wray and E. J. Orwin. Tissue Eng. Part a. 2009, 15, 1463.

[18] J. Wu, Y. Du, S. C. Watkins, J. L. Funderburgh, W. R.Wagner. Biomaterials. 2012, 33, 1343.

[19] M. Ahearne, Y. Yang, A. J. El Haj, K. Then, K. K. Liu. J R Soc Interface, 2005, 2, 455.

[20] M. Ahearne, K. K. Liu, A. J. El Haj, K. Y. Then, S. Rauz , Y. Yang. Tissue Eng Part CMethods. 2010, 16, 319.

[21] Y. Yang, R. K. Wang, E. Guyot, A. Dubois, Q. X. Qin, J. Li, A. J. El Haj, Phys bio med. 2006, 51, 1.

[22] K. Musselmann, B. Alexandrou, B. Kane, J. R. Hassell. J Biol Chem. 2005, 280, 32634

[23] P. A. Barry, H. D. Cavanagh, J. V. Jester. Invest Ophthalmol Vis Sci. 1994, 35, 1356.

[24] M. Funderburgh, Y. Du, M. Mann, N. SundarRaj, J. Funderburgh. FASEB J. 2005, 19, 1371.

[25] Y. Du, N. SundarRaj, M. L. Funderburgh, S. A. Harvey, D.E Birk, J. L Funderburgh. Invest Ophthalmol Vis Sci. 2007, 48, 5038.

[26] A. Kotecha. Surv Ophthalmol 2007, 52, S109.

[27] Y. Yang, I. Wimpenny, M. Ahearne. Nanomed.-Nanotec. Bio Med. 2011, 7, 131.

[28] A. J. Engler, S. Sen, H. L. Sweeney, D. E. Discher. Cell. 2006, 126, 677.

[29] W.W.Y. Kao and C.Y. Liu, Glycoconjugate Journal, 2003, 19, 275

[30] M.L. Funderburgh, Y. Du, M.M. Mann, N. SudarRaj, J.L. Funderburgh, FASEB J. 2005, 10,1371

[31] Y. Pei, R.Y. Reins, A.M. McDermott, Exp Eye Research, 2006, 83, 1063 


\section{Submitted to \\ ADVNNEER
FUNCIONALL \\ 1AAERIAS}

[32] H.B. Hindman, J.N. Swanton, R.P. Phipps, P.J. Sime, K.R. Huxlin, Invest Opthalmol Vis Sci. 2010, 51, 1935

[33]Y,. Pei, D.M. Sherry, A.M. McDermott, Invest Opthalmol Vis Sci, 2003, 44, 869

[34] E.M. Easpana, T. Kawakita, C.Y. Liu, S.C. Tseng, Invest Opthalmol Vis Sci, 2004, 9, 2986

[35] T. Mimura, S. Amano, S. Yokoo, S. Uchida, S. Yamagami, T. Usui, Y. Kimura, Y. Tabata, Molecular Vision, 2008, 14, 1819

[36] B. F. Ju, K. K. Liu. Mech Mater. 2002, 34, 485. 


\section{Submitted to

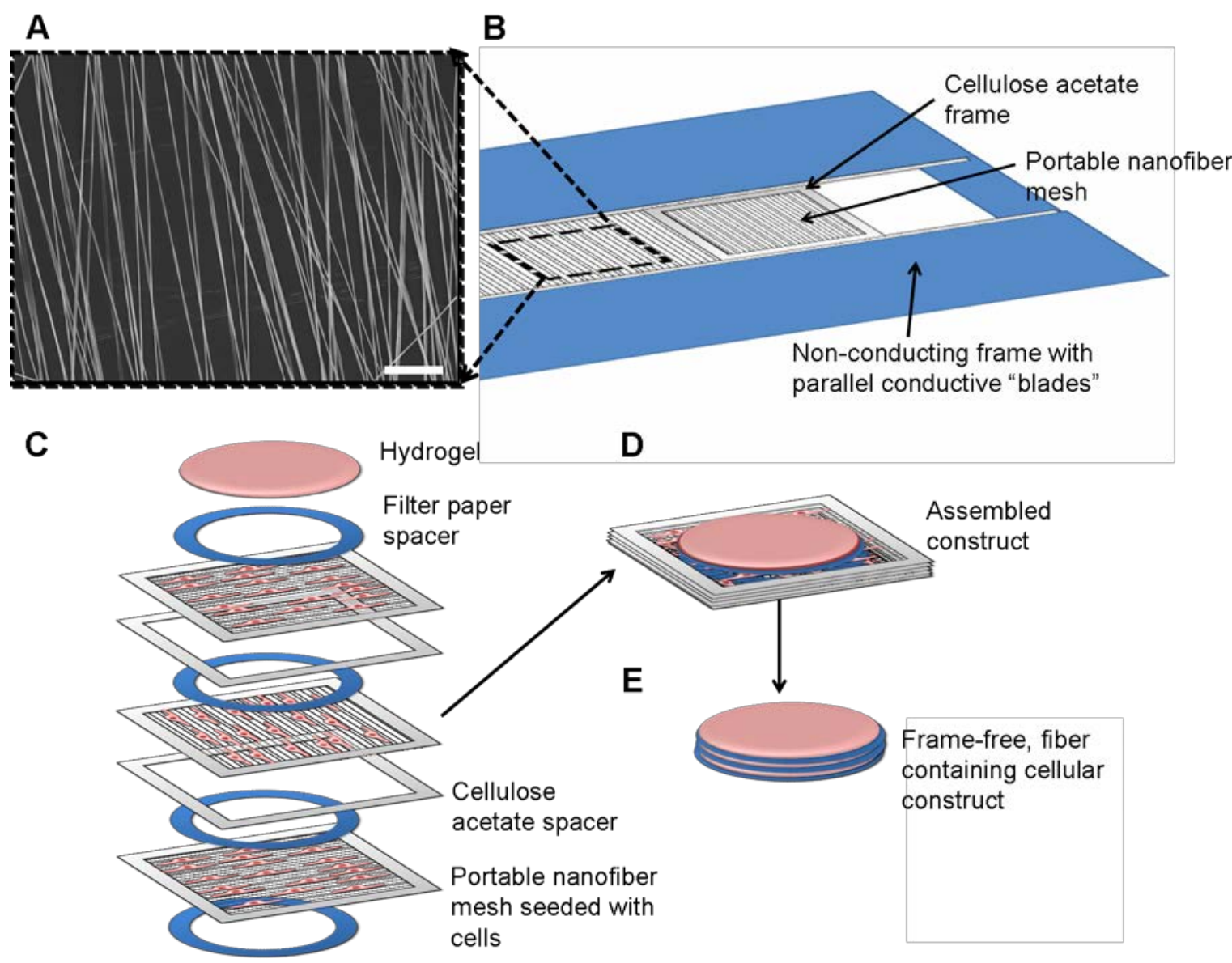

Figure 1: Schematic drawing of the fabrication of aligned portable nanofiber meshes and the organized multi-nanofiber mesh cellular constructs. (A) representative scanning electron microscopy image of aligned electrospun nanofibers, scale bar $=15 \mu \mathrm{m}$; (B) cellulose acetate frames are adhered to the aligned nanofibers and a scalpel is used to sever the frames from the collecting frame; (C) the portable fiber meshes are seeded with cells and arranged orthogonally using a layer-by-layer method with acetate and filter paper spacers between the layers; (D) cells are allowed to attach for 2-3 hrs before collagen is allowed to infiltrate the fibers, securing the fibers within the construct; $(\mathbf{E})$ the excess fibers and acetate frames are removed, forming nanofiber-cellular constructs. 

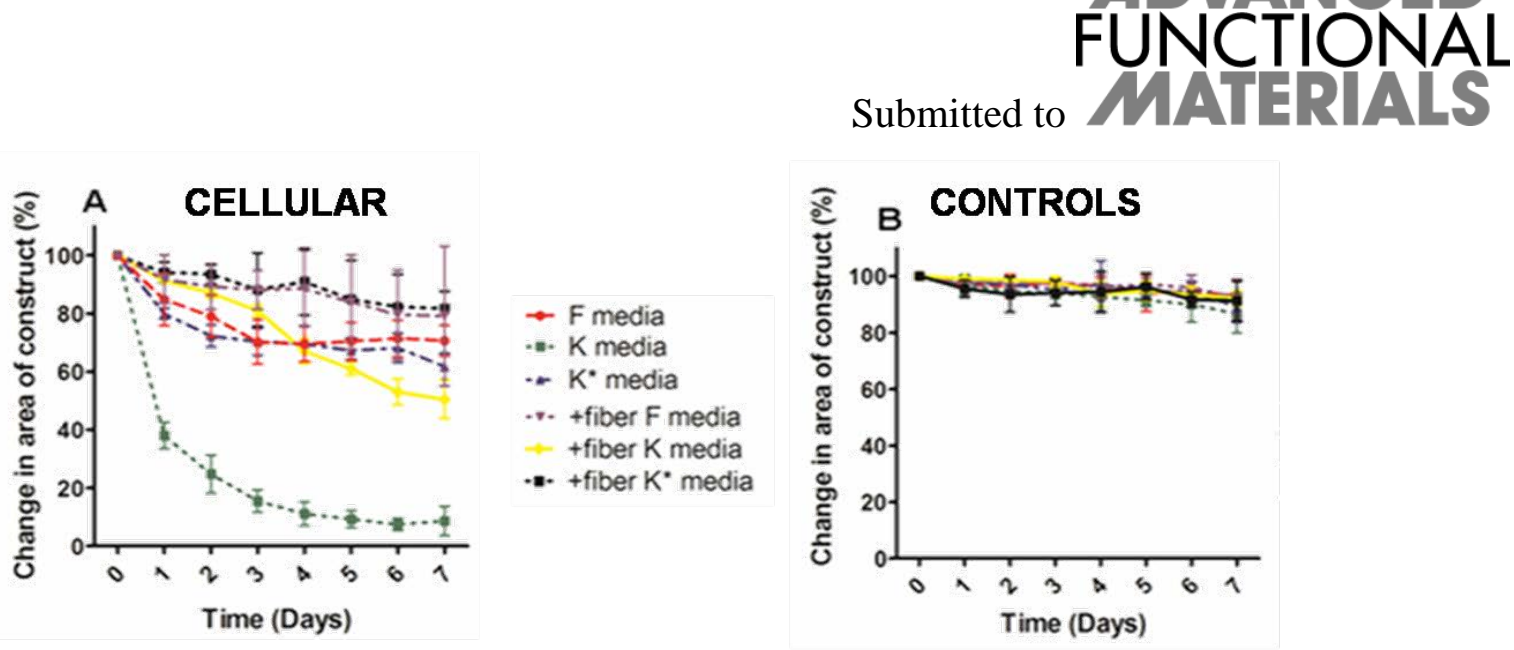

$\rightarrow F$ media

-. K media

- K* media

- + +fiber $\mathrm{F}$ media

+ +fiber K media

-*. +fiber $K^{*}$ media

C

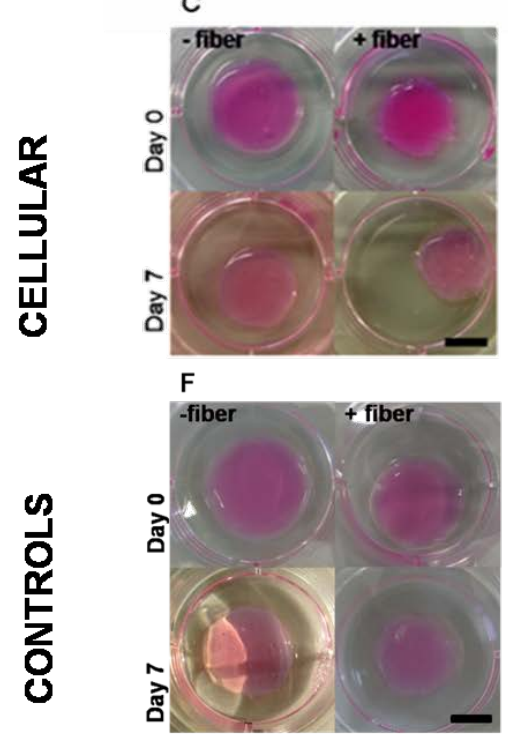

D
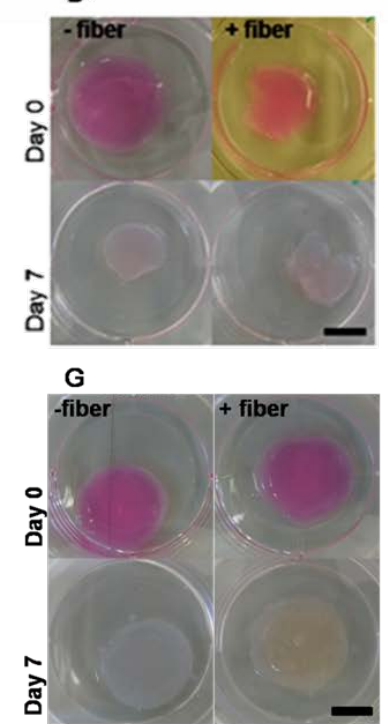

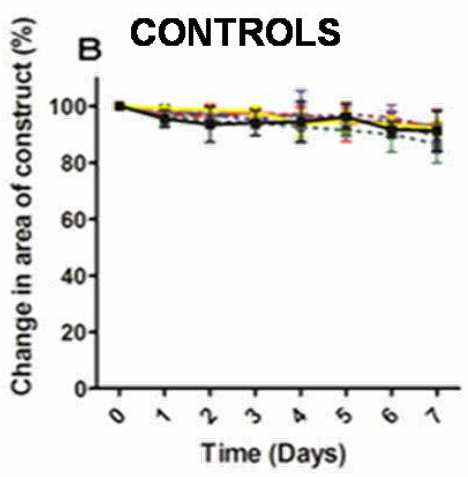

E
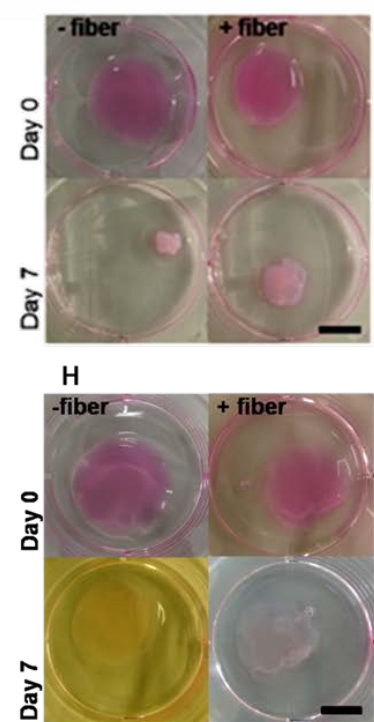

Figure 2: Average change in surface area of non-confined cellular (A) and acellular control

(B) constructs cultured with and without nanofibers under F, K and $\mathrm{K}^{*}$ media respectively for 7 days $(n=6)$; and representative digital images of non-confined hydrogel constructs with $(\mathbf{C}$ E) and without cells (F-H) cultured under (C \& F) K media; (D \& G) K* media; (E \& H) F media with and without the inclusion of nanofibers at day 0 and day 7 . Scale bar $=1 \mathrm{~cm}$. 


\section{FADVANCED}
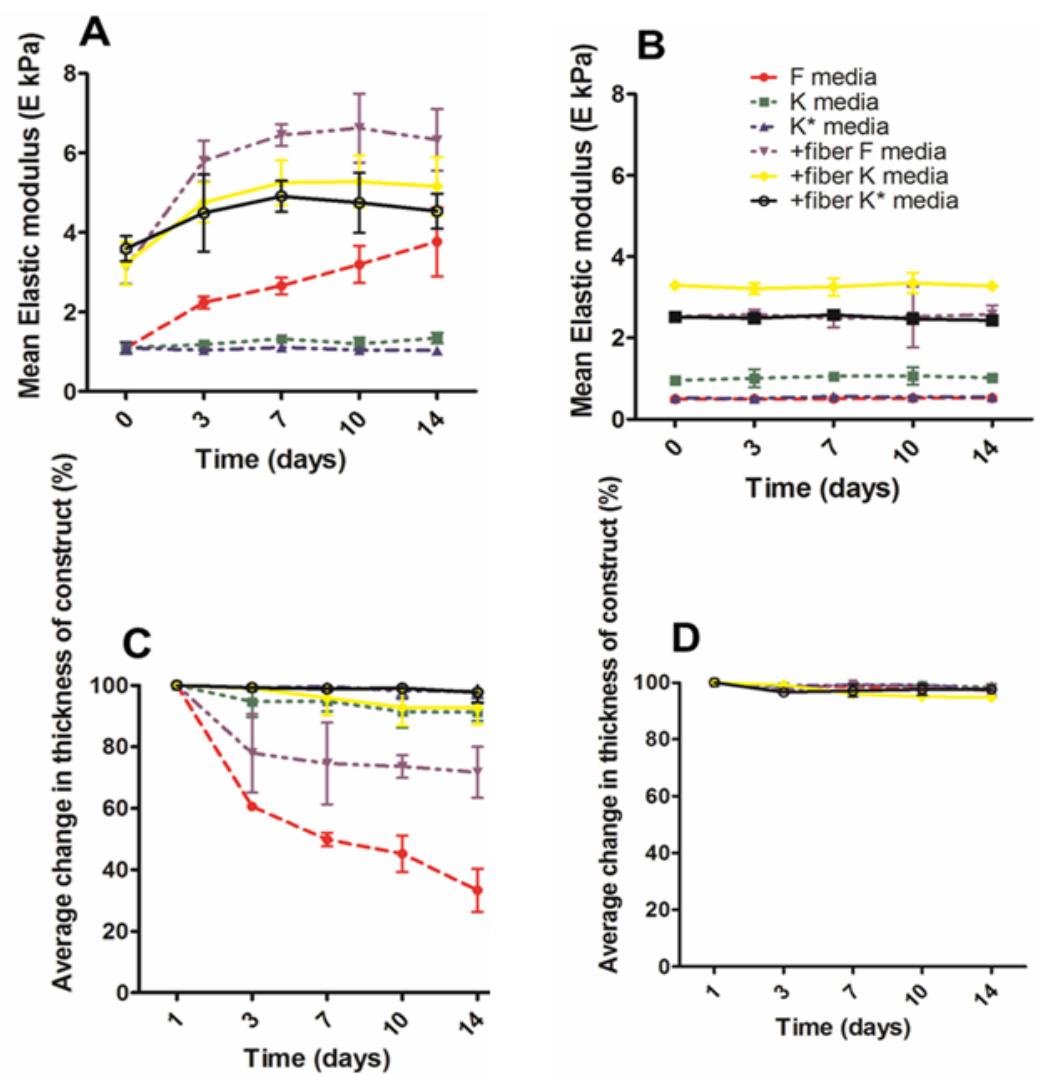

Figure 3: Average elastic modulus of confined cellular (A) and acellular control (B) constructs and average change in thickness of confined cellular (C) and acellular control (D) constructs cultured with and without nanofibers under $\mathrm{F}, \mathrm{K}$ and $\mathrm{K}^{*}$ media respectively for 14 days; $n=6$. 


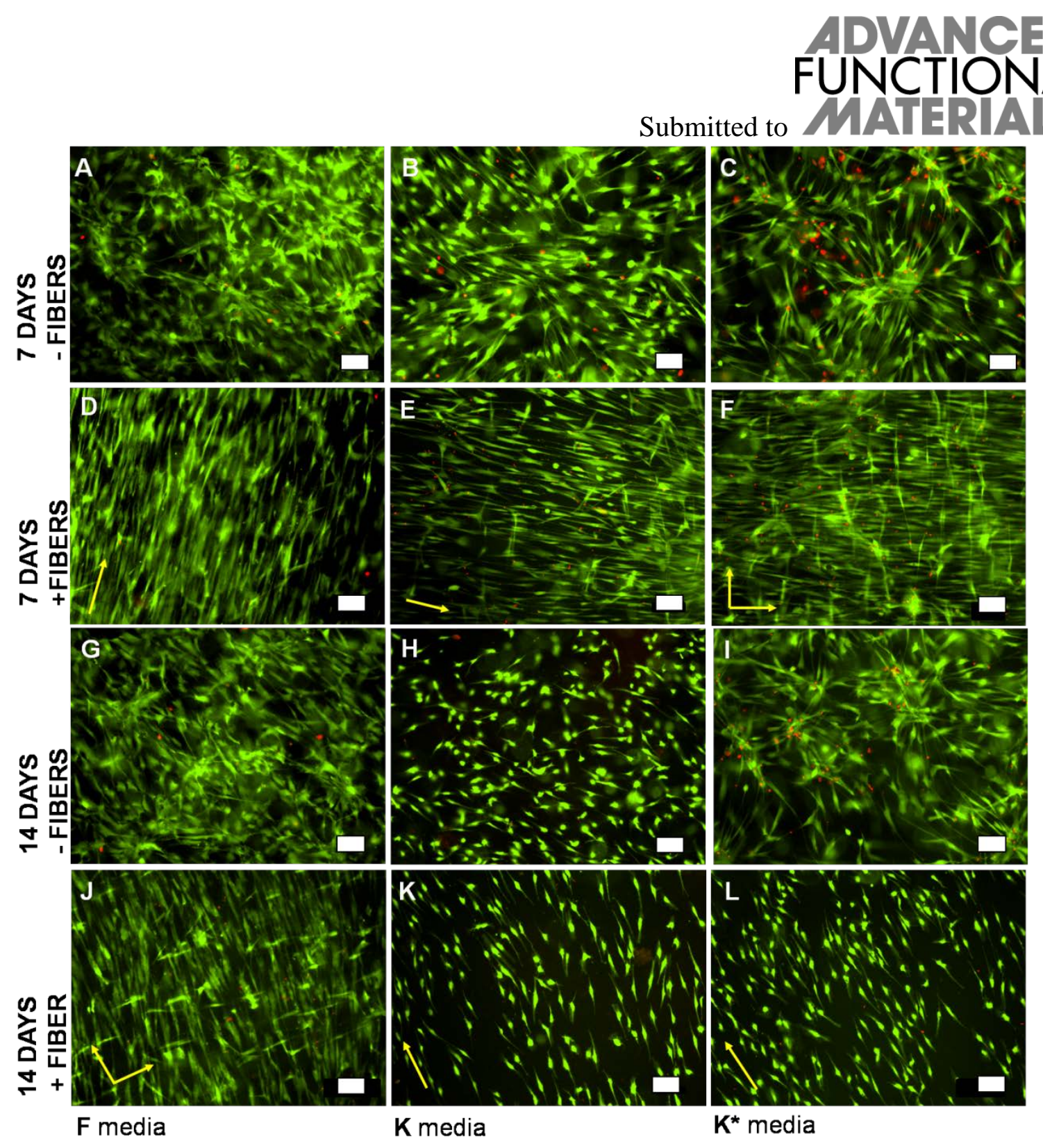

Figure 4: Representative live-dead stained cells, imaged using fluorescent microscopy, of collagen hydrogel constructs following 7(A- F) and 14 (G- L) days culture time under F, K* and K media, respectively. Green indicates live cells and red dead cells. Cells in fiber-free constructs (A-C \& G- I) have grown in a random orientation whereas in the fiber-containing constructs (D- F \& $\mathbf{J}-\mathbf{L})$ the cells are mimicking the orientation of the electrospun nanofibers. The arrows demonstrate the direction of the nanofibers and in some images 2 layers of fibers have been captured in the same image (E, F \& J); scale bar $=100 \mu \mathrm{m}$. 


\section{Submitted to \\ FUNVANCED \\ MATERIALS}

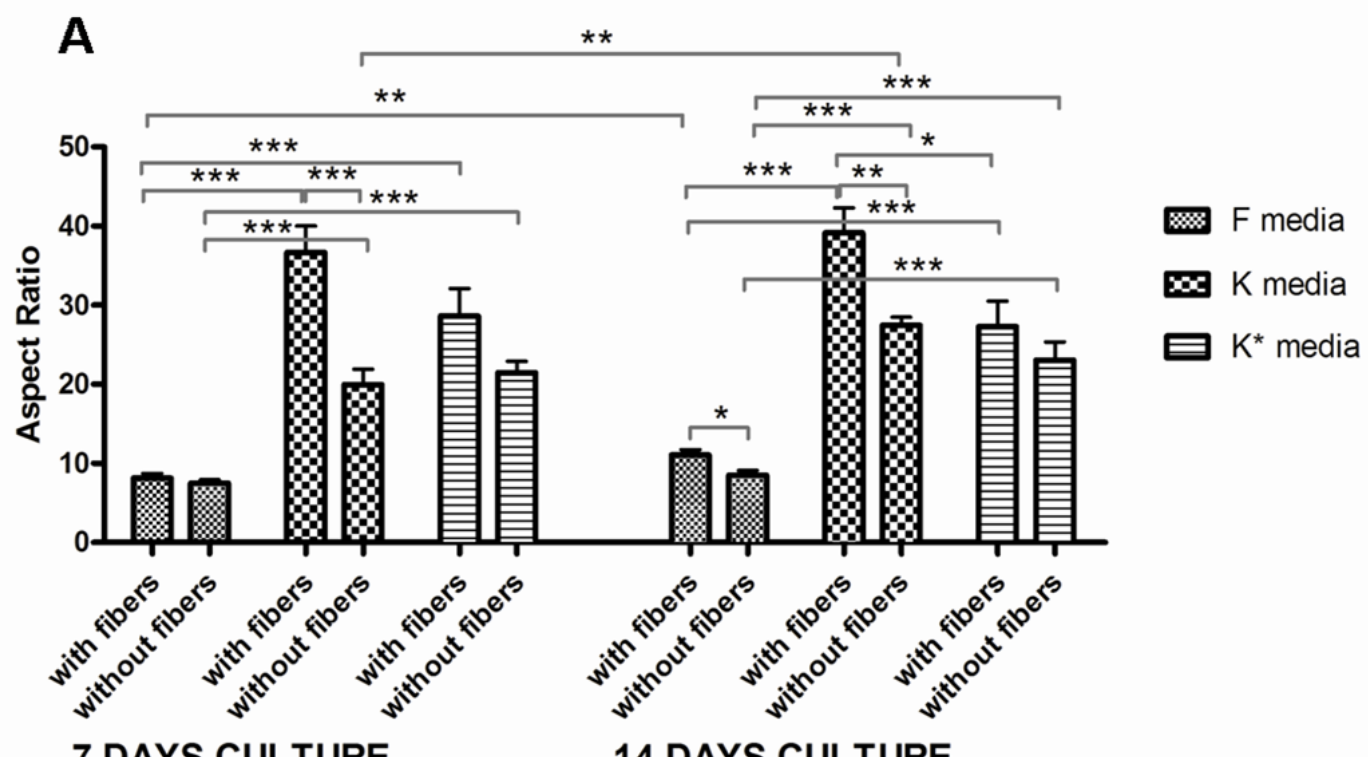

7 DAYS CULTURE

14 DAYS CULTURE

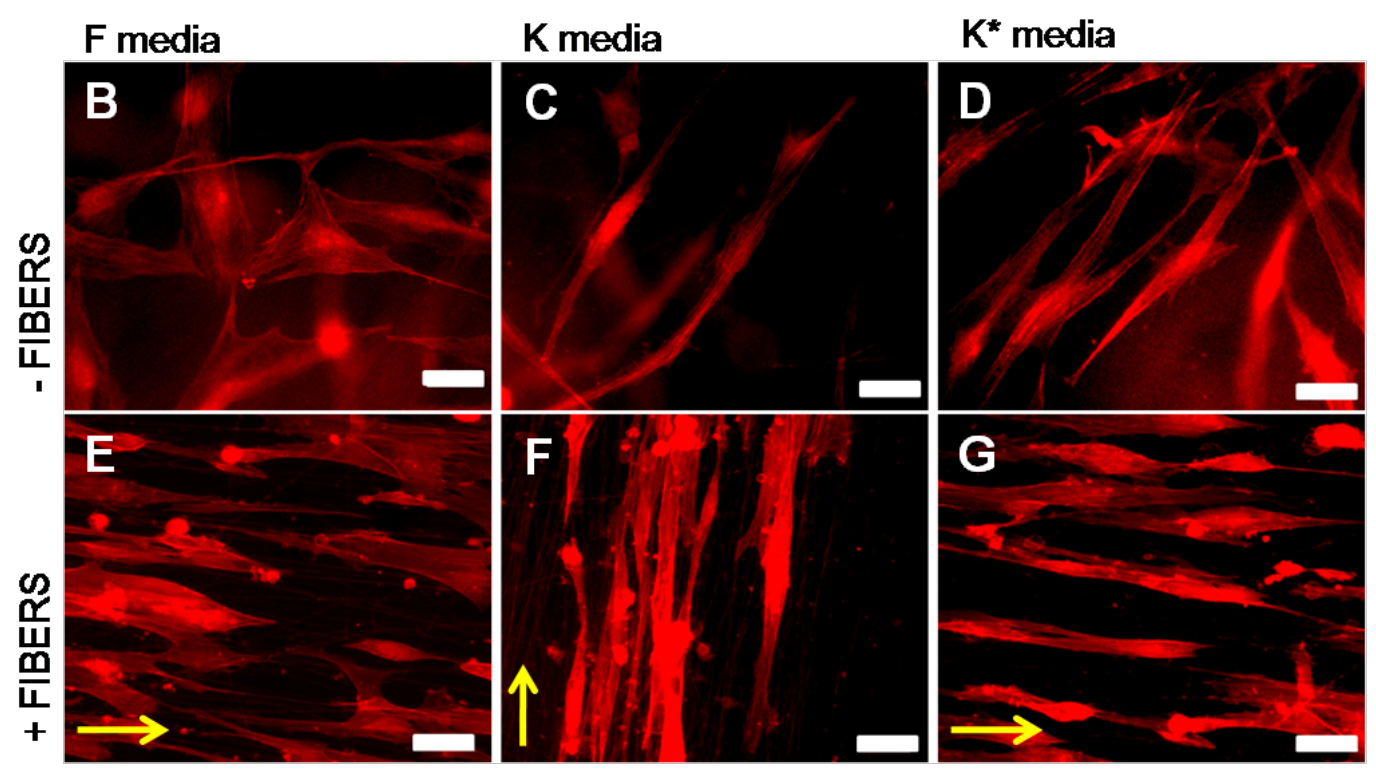

Figure 5: (A) Average aspect ratio for AHDCS cells seeded in the hydrogel constructs with and without the inclusion of nanofibrous mehses cultured under $\mathrm{F}, \mathrm{K}$ and $\mathrm{K}^{*}$ media for 7 and 14 days. $* \mathrm{p} \leq 0.05, * * \mathrm{p} \leq 0.01, * * * \mathrm{p} \leq 0.001$ and representative phalloidin

tetramethyylrhodamine-B-isothiocyanate stained cells, imaged using fluorescent microscopy of collagen hydrogel constructs with (B-C) and without the incorporation of nanofibrous meshes (E-G) following 14 days culture in F, $\mathrm{K}$ and $\mathrm{K}^{*}$ media respectively. When cultured in fiber-free constructs cells grown in serum-containing F media had a shorter, fusiform morphology (B), compared to the more elongated morphology of cells cultured in serum-free 


\section{Submitted to}

$\mathrm{K}$ and $\mathrm{K}^{*}$ media $(\mathbf{C} \& \mathbf{D}$. The addition of nanofibers increased organization within the constructs and encouraged all cells to align and adopt a more elongated morphology (E-G), yellow arrows indicate direction of fibers, scale bar $=50 \mu \mathrm{m}$. 


\section{Submitted to

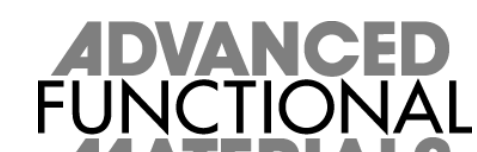

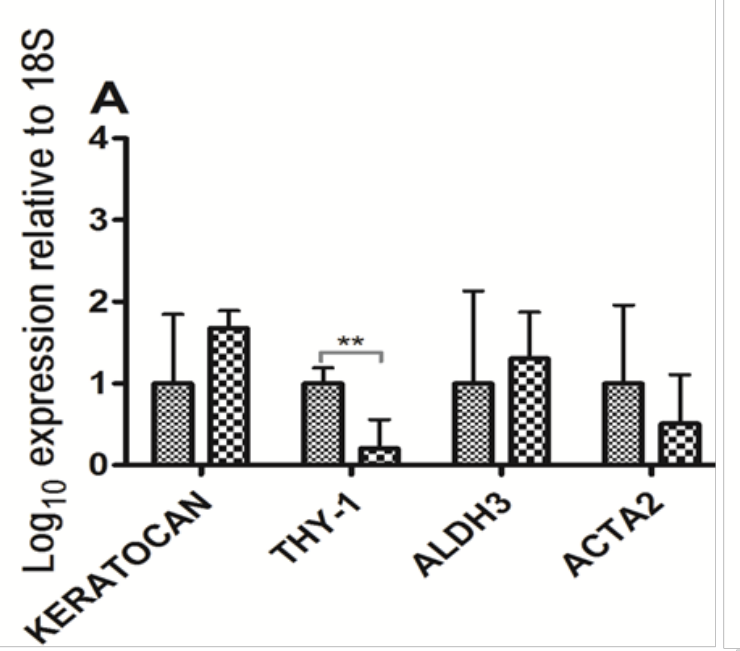
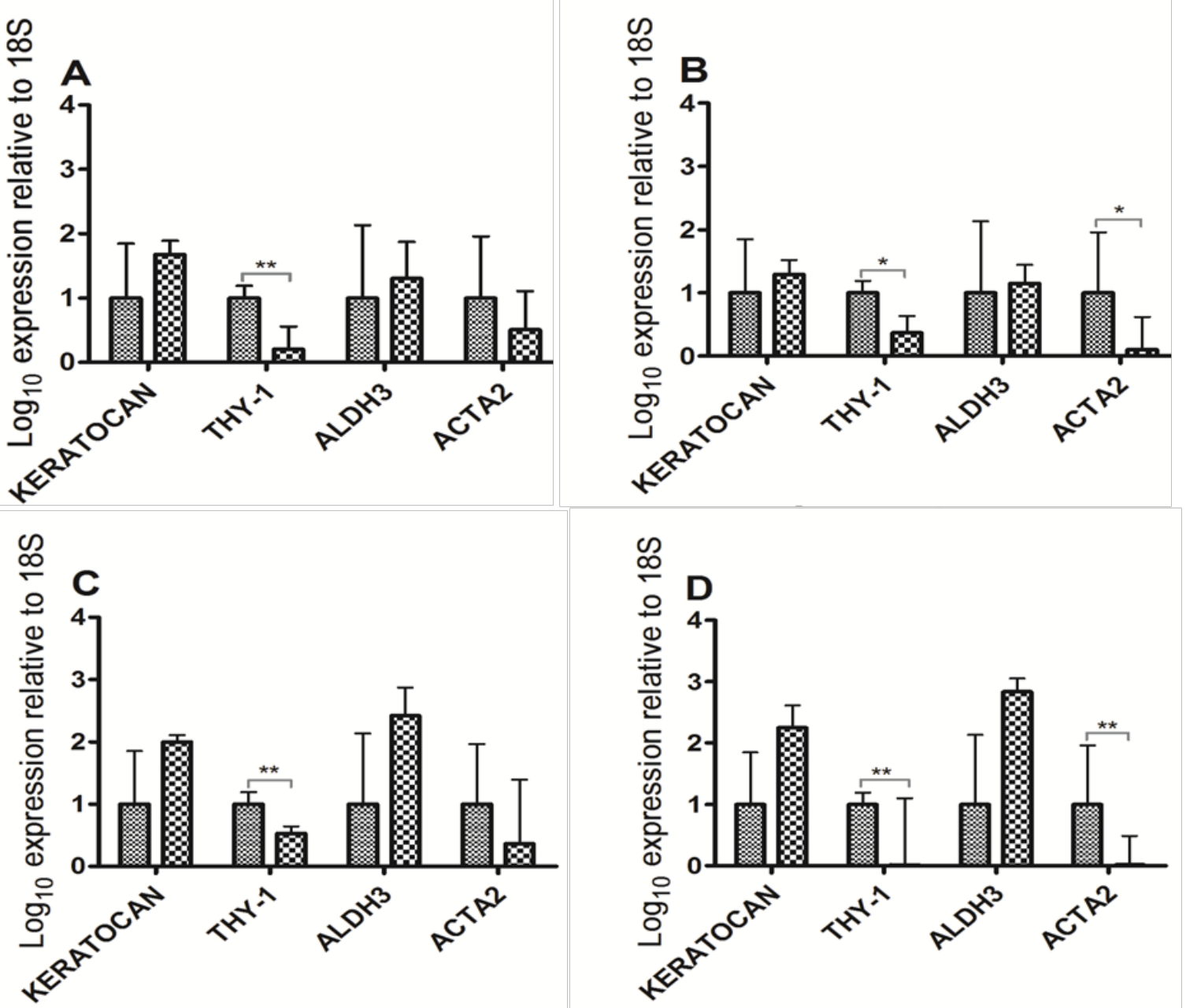

\# TCP $\mathbf{B}$ Collagen Hydrogel

Figure 6: qPCR confirmation of the effect of culture conditions of AHDCS cells in 2D monolayer (TCP) culture vs. 3D collagen hydrogel culture under F media for 7 (A \& B) and 14 (C \& D) days in fiber-free (A \& C) and fiber-containing (B \& D) constructs. * p $\leq 0.05$, $* * \mathrm{p} \leq 0.01, * * * \mathrm{p} \leq 0.001 ; \mathrm{n}=6$ 
Submitted to
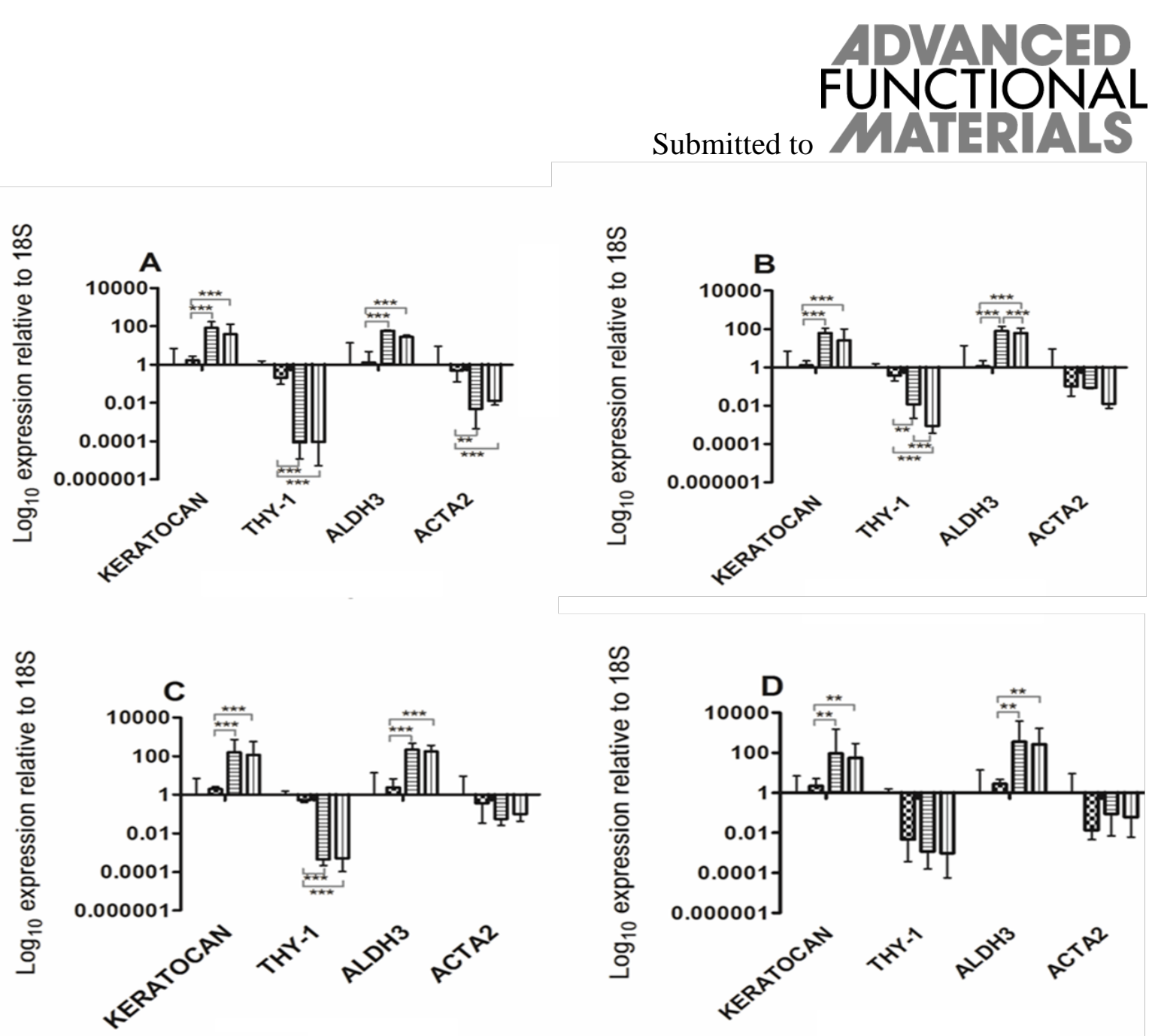

ख TCP $\circledast \mathrm{F}$ media $\boxminus \mathrm{K}$ media 血 $\mathrm{K}^{\star}$ media

Figure 7: qPCR confirmation of the effect of chemical cues (F, K and $\mathrm{K}^{*}$ media) and topographical cues (nanofibers) on the expression of keratogenic and fibroblastic markers at 7 (A \& B) and 14 (C \& D) days in fiber-free (A \& C) and fiber-containing (B \& D) constructs. $* \mathrm{p} \leq 0.05, * * \mathrm{p} \leq 0.01, * * * \mathrm{p} \leq 0.001 . \mathrm{n}=6$. 


\section{Submitted to \\ FUNCTIONAL}

Table 1: The name of the demand primer/probe genes and assay identification numbers

designated by Applied Biosystems.

\begin{tabular}{lll}
\hline Primer name & Abbreviation & Assay Identification \\
\hline Keratocan & KERAT & HS00559942_m1 \\
Thy-1 & THY-1 & HS00174816_m1 \\
Aldehyde Dehydrogenase 3 & ALDH3/ALDH 3 & HS00964880_m1 \\
$\alpha$-Smooth Muscle Actin & ACTA2/a-SMA & HS00909449_m1 \\
Eukaryotic 18S & 18S & Hs99999901_s1
\end{tabular}




\section{Table of Contents entry}

Submitted to

\section{FUNCTIONAL \\ MATERIALS}

A novel engineering strategy was devised to create a nanofiber-hydrogel composite scaffold, which displayed the characteristic morphological cues of native corneal tissue. Investigation of cell response to nanofibrous topographical cues, combined with media supplementation, highlighted that orthogonal arrangement of AHDCS cells in a 3D constructs with the presence of insulin and ascobate promotes keratogenesis, which could be a new strategy for generation of complex corneal tissue.

Keyword: Biomedical applications

I. Wimpenny, M. Ahearne, S. Rauz, A. J. El Haj*, Y. Yang*

Chemical and Topographical Effects on Cell Differentiation and Matrix Elasticity in a Corneal Stromal Layer Model.

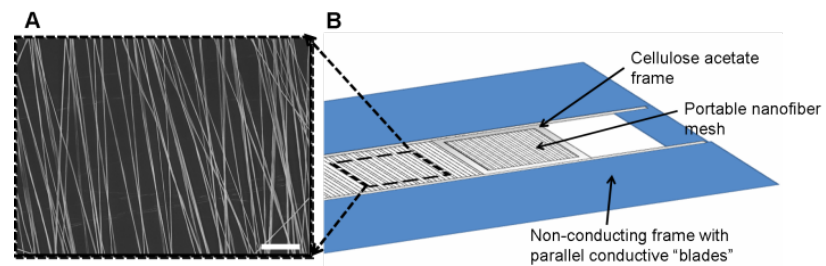

c

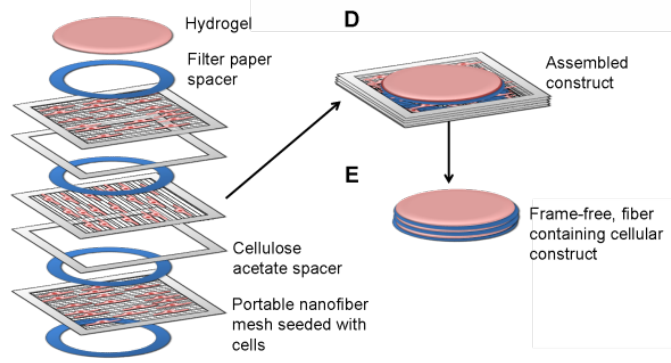

